\title{
Smoking and Related Factors during Pregnancy
}

\author{
Ayşe Önal Aral ${ }^{1}$, Serdar Yalvaç²
}

${ }^{1}$ Clinic of Chest Diseases, Etlik Zübeyde Hanım Obstetrics and Gynecology Training and Research Hospital, Ankara, Turkey ${ }^{2}$ Clinic of Perinatology, Etlik Zübeyde Hanım Obstetrics and Gynecology Training and Research Hospital, Ankara, Turkey

\begin{abstract}
Objective: In this study, we aimed to investigate smoking habits of women during pregnancy and determine the related factors.

Methods: In this cross-sectional study, a total of 1021 women were included in the first $24 \mathrm{~h}$ after they gave birth in the hospital between March and May 2014. The study was conducted at only one hospital. Participants were interviewed face-to-face by researchers using a questionnaire. Data were analyzed using IBM SPSS Statistics for Windows v.22.0. The relation between categorical variables was determined using chi-square test. Statistical significance was achieved when the $p$ value was less than 0.05 . Ethics committee approval from the hospital and written informed consent from the participants were obtained for the study.
\end{abstract}

Results: The frequency of smoking during pregnancy was $13.0 \%$. The majority smoked until birth (10.1\%). Household smoker was significantly associated with smoking during pregnancy $(\mathrm{p}<0.001)$, and advanced maternal age ( $>35$ years) during pregnancy was associated with smoking until birth during pregnancy $(\mathrm{p}<0.05)$.

Conclusion: The prevalence of smoking was still high among pregnant women in spite of strict measures and all efforts against smoking in Turkey. Advanced maternal age and household smoker were associated with smoking during pregnancy. Special focus is needed on the issue of smoking during pregnancy not only by pregnant women but also by their household's members.

Keywords: Smoking, smoker, pregnancy

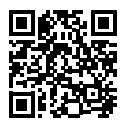

Received Date: 23.07.2015 Accepted Date: 14.11 .2015 Available Online Date: 11.01 .2016

DOI: $10.5152 /$ ejp.2015.58076

Correponding Author Ayşe Önal Aral

E-mail:aonal2@yahoo.com

- Available online at www.eurasianjpulmonol.com

This work is licensed under a Creative Commons Attribution-NonCommercial 4.0 International License.

\section{INTRODUCTION}

Smoking during pregnancy has long been considered as one of the important risk factors for perinatal adverse outcomes. Risk of ectopic pregnancy, spontaneous abortion, placenta previa, and placental abruption in mothers as well as preterm birth, low birth weight, and potentially carcinogenic genetic mutations in babies are among harmful effects that could be resulted from smoking during pregnancy (1-4). Smoking among pregnant women is prevalent in not only Turkey but also other countries all over the world, although its adverse effects have been known.

In the studies conducted in Turkey during the last 10 years, the prevalence of smoking among pregnant women was found to be between $9.7 \%$ and $22.7 \%$ (5-8). In another study conducted recently, which included 15 countries, it was found that the prevalence of smoking during pregnancy was $14.2 \%$ in France, $9.7 \%$ in Russia, $10.5 \%$ in Italy, $6.9 \%$ in England, $5.4 \%$ in Switzerland (9). In Turkey, areas in which tobacco products are used have been quite restricted by the legislation in 2008 for preventing and controlling the harmful effects of tobacco products. According to the Global Adult Tobacco Study 2012 in Turkey, tobacco use decreased by $13.4 \%$ between 2008 and 2012 and the prevalence of smoking was $13.1 \%$ for women (10).

Smoking during pregnancy needs to be given attention to elucidate the related factors and to acquire successful outcomes in terms of preventive and other strategies on the issue. Our aim in this study was to investigate not only smoking habits of pregnant women but also frequency of smoking during pregnancy. The results were compared with those of previous studies in Turkey to if there were 
any changes with time. In addition, we investigated factors related to smoking during pregnancy such as age, education, and smoking status of other household members in addition to the partner.

\section{METHODS}

The study was designed as a cross-sectional study. A total of 1021 women were included in the study in the first $24 \mathrm{~h}$ after they gave birth in the hospital where the study was conducted between March and May 2014.The study was conducted at only one hospital. Participants were interviewed face-to-face by researchers after obtaining written informed consent and approval from the hospital's ethics committee for the study before the study started. The questionnaire including questions explained below and was used for collecting the information from participants.

All participants were questioned on age, education, partner smoking status, and other household members' smoking status in addition to their smoking status. Women smoking during pregnancy were questioned on their daily cigarette consumption and if they had received any advice or support from health care centers for quitting smoking during that period. Those who stopped smoking at the onset of pregnancy or during the pregnancy term were questioned on the reasons for which they stopped smoking and if they intended to restart smoking after delivery. Women who did not smoke during pregnancy were questioned if they were exposed to cigarettes smoke at home or at workplace.

The participants were grouped into two categories according to their smoking history.

Group 1. Did not smoke during pregnancy (i.e., non-smokers during pregnancy): Women who did not smoke throughout the pregnancy. This group was subdivided into two categories

Group 1a. Non-smoker: These women were non-smokers before pregnancy and did not smoke during pregnancy. Women who used to smoke before but were non-smokers at the onset of pregnancy were also included.

Group 1b. Stopped smoking: These women were smokers before pregnancy but stopped at the onset of pregnancy.

Group 2. Smoked during pregnancy (i.e., smokers during pregnancy): This group was subdivided into two categories

Group 2a. Smoked for some time during pregnancy (at least for 1 month)

Group 2b. Smoked until birth

Household smoker was subdivided into two groups as "partner", who was married the participant and living in the same home, and "an- other person", who was a family member such as mother-in-law and living in the same home.

\section{Statistical Analysis}

Data were analyzed using IBM Statistical Package for the Social Sciences (SPSS) Statistics for Windows v.22.0. The relation between categorical variables was determined using Chi-square test. Statistical significance was achieved when the $p$ value was less than 0.05 .

\section{RESULTS}

A total of 1021 women participated in the study. Although $89.7 \%$ (916) of the participants were between 18 and 35 years of age, 10.3\% (105) were older than 35 . The proportion of non-smoker was $82.8 \%$ (846),those who stopped smoking was $4.1 \%(42)$, those who smoked for some time was $2.8 \%$ (29), and those who smoked until birth was $10.1 \%$ (104).The frequency of smoking during pregnancy was $13.0 \%$. Table 1 shows smoking habits of participants during pregnancy according to age, education, and household smoker. The proportion of those who smoked until birth was higher in the group of women who were older than 35 years, in the group of illiterate women, and among those who had household smokers. The proportion of smoker partner was high both in the group of non-smokers and smokers during pregnancy, with a higher rate in the latter group $(50.7 \%$ and $68.4 \%$, respectively). In the study group, $5.5 \%$ of all participants had a smoker partner and another smoker person at home. Most of the smokers during pregnancy smoked between 1 and 5 cigarettes per day (81.2\%). The proportion of pregnant women receiving advice from health care workers such as doctors and nurses for smoking cessation was $49.6 \%$ among the smokers during pregnancy. The proportion of those who stopped smoking at the onset or within the pregnancy period because of thought that smoking would be harmful to their baby was $80.6 \%$, whereas $1.4 \%$ quit smoking because of nausea and $18.1 \%$ quit because of both of the above reasons. The proportion of those who intended to resume smoking after delivery was $38.3 \%$ among those who stopped smoking at the onset or within the pregnancy period. The highest rate of tobacco smoke exposure was at home, with the rate of $27.3 \%$, whereas it was $0.6 \%$ at workplace and $0.1 \%$ at home plus workplace among non-smokers during pregnancy.

Smoking during pregnancy was found to be significantly associated with household smoker $(p<0.001)$ (Table 2$)$.

Among smokers during pregnancy, smoking until birth was found to be associated with household smoker $(p<0.05)$ and advanced maternal age $(p<0.05)$ (Table 3$)$.

Table 1. Distribution of the smoking habits among pregnants according to age, education, and household smoker

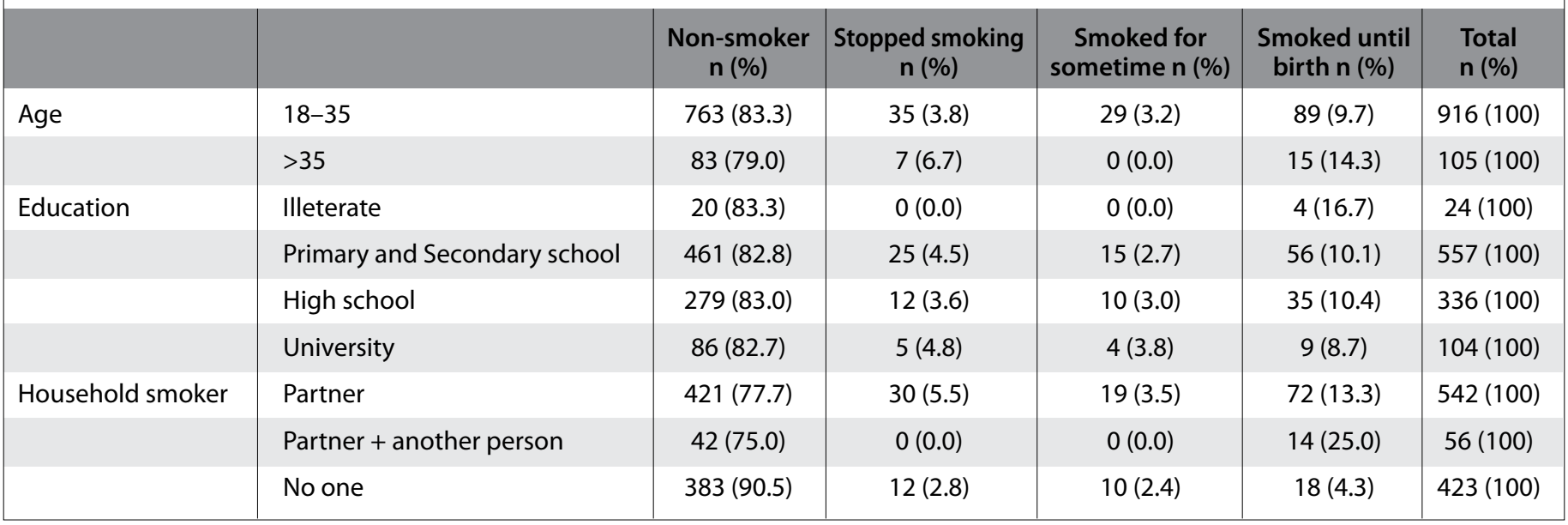




\begin{tabular}{|c|c|c|c|c|c|}
\hline & & $\begin{array}{c}\text { Did not } \\
\text { smoke during } \\
\text { pregnancy } \mathrm{n}(\%)\end{array}$ & $\begin{array}{l}\text { Smoked during } \\
\text { pregnancy } \\
n(\%)\end{array}$ & $\begin{array}{l}\text { Total } \\
\text { n (\%) }\end{array}$ & $\mathbf{p}$ \\
\hline Household smoker & $\begin{array}{l}\text { Partner } \\
\text { Partner + another person } \\
\text { No one }\end{array}$ & $\begin{array}{l}451(83.2) \\
42(75.0) \\
395(93.4)\end{array}$ & $\begin{array}{l}91(16.8) \\
14(25.0) \\
28(6.6)\end{array}$ & $\begin{array}{l}542(100) \\
56(100) \\
423(100)\end{array}$ & $0.000^{* * * *}$ \\
\hline Age & $\begin{array}{l}18-35 \\
>35\end{array}$ & $\begin{array}{c}798(87.1) \\
90(85.7)\end{array}$ & $\begin{array}{c}118(12.9) \\
15(14.3)\end{array}$ & $\begin{array}{l}916(100) \\
105(100)\end{array}$ & 0.648 \\
\hline Education & $\begin{array}{l}\text { Illeterate } \\
\text { Primary and Secondary school } \\
\text { High school } \\
\text { University }\end{array}$ & $\begin{array}{l}20(83.3) \\
486(87.3) \\
291(86.6) \\
91(87.5)\end{array}$ & $\begin{array}{l}4(16.7) \\
71(12.7) \\
45(13.4) \\
13(12.5)\end{array}$ & $\begin{array}{l}24(100) \\
557(100) \\
336(100) \\
104(100)\end{array}$ & 0.943 \\
\hline
\end{tabular}

Table 3. An univariate analysis of associated factors for the group of smoked for some time during pregnancy and the group of smoked until birth

\begin{tabular}{|c|c|c|c|c|c|}
\hline & & $\begin{array}{l}\text { Smoked for } \\
\text { some time during } \\
\text { pregnancy } n(\%)\end{array}$ & $\begin{array}{l}\text { Smoked until } \\
\text { birth } \\
n(\%)\end{array}$ & $\begin{array}{l}\text { Total } \\
\text { n (\%) }\end{array}$ & $p$ \\
\hline Household smoker & $\begin{array}{l}\text { Partner } \\
\text { Partner + another person } \\
\text { No one }\end{array}$ & $\begin{array}{c}19(20.9) \\
0(0.0) \\
10(35.7)\end{array}$ & $\begin{array}{l}72(79.1) \\
14(100) \\
18(64.3)\end{array}$ & $\begin{array}{l}91(100) \\
14(100) \\
28(100)\end{array}$ & $0.028^{*}$ \\
\hline Age & $\begin{array}{l}18-35 \\
>35\end{array}$ & $\begin{array}{c}29(24.6) \\
0(0.0)\end{array}$ & $\begin{array}{l}89(75.4) \\
15(100)\end{array}$ & $\begin{array}{c}118(100) \\
15(100)\end{array}$ & $0.041^{*}$ \\
\hline Education & $\begin{array}{l}\text { Illeterate, } \\
\text { Primary and Secondary school } \\
\text { High school } \\
\text { University }\end{array}$ & $\begin{array}{l}15(20.0) \\
10(22.2) \\
4(30.8)\end{array}$ & $\begin{array}{l}60(80.0) \\
35(77.8) \\
9(69.2)\end{array}$ & $\begin{array}{l}75(100) \\
45(100) \\
13(100)\end{array}$ & 0.684 \\
\hline Total & & $29(21.8)$ & $104(78.2)$ & $133(100)$ & \\
\hline
\end{tabular}

In addition, we found that smoking until birth was associated with household smoker in the univariate analysis of associated factors for those including the group of non-smokers $(p<0.001)$ and the group of those who stopped smoking $(p<0.05)$.

We did not find any significant relation between education status of women and smoking during pregnancy in univariate analysis in this study group ( $p>0.05)$.

\section{DISCUSSION}

In our study, frequency of smoking during pregnancy was $13.0 \%$. Recently, in Turkey, this rate was reported to be $11.4 \%$ (8). Smoking frequency among pregnant women was still high, although it has been declared that tobacco use decreased in Turkey after legislation related to tobacco use was introduced in 2008 (10). In addition, the rate reported in this study was found to be higher than that reported in many other countries (9).

The proportion of smokers during pregnancy was higher in the group older than 35 years compared to the group aged between 18 and 35 years (Table 1). This finding was contrary to those reported in other studies $(7,11)$. Moreover, in univariate analysis, we found that smoking until birth was associated with advanced maternal age (Table 3). Pregnant women aged older than 35 years are considered to be at a higher risk for adverse perinatal outcomes $(12,13)$. Smoking during pregnancy for this age group could add burden and worsen adverse perinatal outcomes (11).

The frequency of smoking was higher among the illiterate group compared to the educated group (Table 1). This finding was consistent with one study and was contrary to another study in Turkey (7, $8)$. This result may be attributed to poor socioeconomic conditions that pregnant women in this group face (7).

In univariate analysis, we found that smoking during pregnancy was significantly associated with household smoker (Table 2). This finding was consistent with other studies $(7,8)$. Studies have shown that smoker partner can facilitate women starting smoking and may also make it difficult for smoker women to quit smoking $(14,15)$. In this study if there was another smoker person in the same home in addi- 
tion to a smoker partner, the proportion of women who smoked until birth was significantly higher among smokers during pregnancy (Table 3). In other words, if there were more than one smoker at home, smoker pregnant women in this study group most likely smoked until birth instead of stopping smoking during her pregnancy. The risk of low birthweight baby does not occur among pregnant women if they quit smoking in the early period of pregnancy (16).

Only $49.6 \%$ of smokers during pregnancy had received verbal advice from health care workers for quitting smoking in our study. None of them had received professional support. In other words, half of pregnant women were not questioned for smoking, and therefore, had not received advice or support from health care facilities for stopping smoking. This result was consistent with another study in Turkey (10).

Smoking cessation interventions during pregnancy reduce the proportion of women who continue to smoke, thereby reducing low birthweight and preterm birth (17).

The proportion of women who stopped smoking at the onset or during pregnancy and stated that they intended to resume smoking after delivery was $38.3 \%$. This finding was in accordance with another study declaring this rate to be $43 \%$ (18). This finding suggested that some of the non-smokers during pregnancy would be smoker in near future if any effective intervention for quitting smoking was not implemented on them.

Most of those who stopped smoking at the onset or within pregnancy period stated that they knew that smoking would be harmful to their baby so they decided quitting smoking. This suggested that addressing to this sensibility might help to get successful outcomes in interventions for quitting smoking during pregnancy period.

The proportion of non-smokers during pregnancy who were exposed cigarettes smoke at home during pregnancy was $27.3 \%$. The risk of low birthweight baby and baby with congenital abnormality is high among women exposed to environmental cigarettes smoke during pregnancy, even if they are non-smokers (19).

The limitation of our study was that data were obtained based on participants' reports and their partner's smoking habits. Therefore, women may have underreported their own smoking status in particular.

\section{CONCLUSION}

Consequently, frequency of smoking among pregnant women is still high and essential regulations taking smoking status of household members into account are needed on the issue of smoking during pregnancy in Turkey.

Ethics Committee Approval: Ethics committee approval was received for this study from the ethics committee of Etlik Zübeyde Hanım Obstetrics and Gynecology Training and Research Hospital, Ankara.

Informed Consent: Written informed consent was obtained from patients who participated in this study.

Peer-review: Externally peer-reviewed.

Author Contributions: Concept - A.Ö.A.; Design - A.Ö.A., S.Y.; Supervision - A.Ö.A., S.Y.; Resources - A.Ö.A., S.Y.; Materials - S.Y.; Data Collection and/or Processing - A.Ö.A.; Analysis and/or Interpretation - A.Ö.A.; Literature Search A.Ö.A.; Writing Manuscript - A.Ö.A.; Critical Review - A.Ö.A., S.Y.; Other - A.Ö.A.
Acknowledgements: We, as authors of this study, gratefully acknowledge the support and generosity of Turkish Respiratory Society in statistical analysis of the present study.

Conflict of Interest: No conflict of interest was declared by the authors.

Financial Disclosure: The authors declared that this study has received no financial support.

\section{REFERENCES}

1. Polańska K, Hanke W. Effect of smoking during pregnancy on maternal condition and birth outcome--overview of epidemiologic studies. $\mathrm{Pr}$ zegl Epidemiol 2004; 58: 683-91.

2. Horta BL1, Victora CG, Menezes AM, Halpern R, Barros FC. Low birthweight, preterm births and intrauterine growth retardation in relation to maternal smoking. Paediatr Perinat Epidemiol 1997; 11: 140-51. [CrossRef]

3. Lackmann GM, Salzberger U, Töllner U, Chen M, Carmella SG, Hecht SS. Metabolites of a tobacco-specific carcinogen in urine from newborns. J Natl Cancer Inst 1999; 91: 459-65. [CrossRef]

4. Anderson KE, Carmella SG, Ye M, Bliss RL, Le C, Murphy L, et al. Metabolites of a tobacco-specific lung carcinogen in nonsmoking women exposed to environmental tobacco smoke. J Natl Cancer Inst 2001; 93: 378-81. [CrossRef]

5. Uncu Y, Ozcakir A, Ercan I, Bilgel N, Uncu G. Pregnant women quit smoking; what about fathers? Survey study in Bursa Region, Turkey. Croat Med J 2005; 46: 832-7.

6. Karcaaltincaba D, Kandemir O, Yalvac $S$, Güven ES, Yildirim BA, Haberal A. Cigarette smoking and pregnancy: results of a survey at a Turkish women's hospital in 1,020 patients. J Obstet Gynaecol 2009; 29: 480-6. [CrossRef]

7. Ergin I, Hassoy H, Tanik FA, Aslan G. Maternal age, education level and migration: socioeconomic determinants for smoking during pregnancy in a field study from Turkey. BMC Public Health 2010; 10: 325. [CrossRef]

8. Aslan D, Şengelen M, Çağatay P. Factors Related to Smoking Status of Pregnant Women Aged 15-49 in Turkey. Turk Thorac J 2014; 15: 27-32. [CrossRef]

9. Smedberg J, Lupattelli A, Mårdby AC, Nordeng H. Characteristics of women who continue smoking during pregnancy: a cross-sectional study of pregnant women and new mothers in 15 European countries. BMC Pregnancy Childbirth 2014; 14: 213. [CrossRef]

10. Global Adult Tobacco Study 2012 in Turkey. Available from: http:// thsk.saglik.gov.tr/2013-10-01-11-00-51/yayinlarimiz.html

11. Lamminpää $R$, Vehviläinen-Julkunen $K$, Gissler M, Heinonen S. Smoking among older childbearing women - a marker of risky health behaviour a registry-based study in Finland. BMC Public Health 2013; 13: 1179. [CrossRef]

12. Lamminpää R, Vehviläinen-Julkunen K, Gissler M, Heinonen S. Preeclampsia complicated by advanced maternal age: a registry-based study on primiparous women in Finland 1997-2008. BMC Pregnancy Childbirth 2012; 12: 47. [CrossRef]

13. Lamminpää $R$, Vehviläinen-Julkunen $K$, Gissler $M$, Selander $T$, Heinonen $S$. Pregnancy outcomes of overweight and obese women aged 35 years or older - A registry-based study in Finland. Obes Res Clin Pract 2015 Jun 5. pii: S1871-403X(15)00072-1. doi: 10.1016/j. orcp.2015.05.008. [Epub ahead of print] [CrossRef]

14. Collins RL, Emont SL, Zywiak WH. Social influence processes in smoking cessation: postquitting predictors of long-term outcome. J Subst Abuse 1990; 2: 389-403. [CrossRef]

15. Sanders D, Peveler R, Mant D, Fowler G. Predictors of successful smoking cessation following advice from nurses in general practice. Addiction 1993; 88: 1699-705. [CrossRef]

16. Suzuki K, Sato M, Zheng W, Shinohara R, Yokomichi H, Yamagata Z. Effect of maternal smoking cessation before and during early pregnancy on fetal and childhood growth. J Epidemiol 2014; 24: 60-6. [CrossRef]

17. Pullon S, McLeod D, Benn C, Viccars A, White S, Cookson T, et al. Smoking cessation in New Zealand: education and resources for use by midwives for 
women who smoke during pregnancy. Health Promot Int 2003; 18: 315-25. [CrossRef]

18. Pollak KI, Fish LJ, Lyna P, Peterson BL, Swamy GK, Levine MD. Predictors of pregnant quitters' intention to return to smoking postpartum. Nicotine Tob Res 2015; 17: 742-5. [CrossRef]
19. Salmasi G, Grady R, Jones J, McDonald SD, Knowledge Synthesis Group. Environmental tobacco smoke exposure and perinatal outcomes: a systematic review and meta-analyses. Acta Obstet Gynecol Scand 2010; 89: 423-41. [CrossRef] 